\title{
ФЕЛИКС ХОЛЬЦНЕР ПРЕДСТАВЛЯЕТ КОМПАНИЮ SWISSLITHO
}

\section{FELIX HOLZNER PRESENTS THE SWISSLITHO}

\author{
А.Н.Алёшин, к.ф.-м.н., дощент, (ORCID: 0000-0001-7342-4638) / nanoindustry@technosphera.ru \\ A.N.Alyoshin, Cand of Sc. (Physics and Mathematics), Docent
}

DOI: 10.22184/1993-8578.2019.12.2.132.134

Получено: 20.03.2019 г.

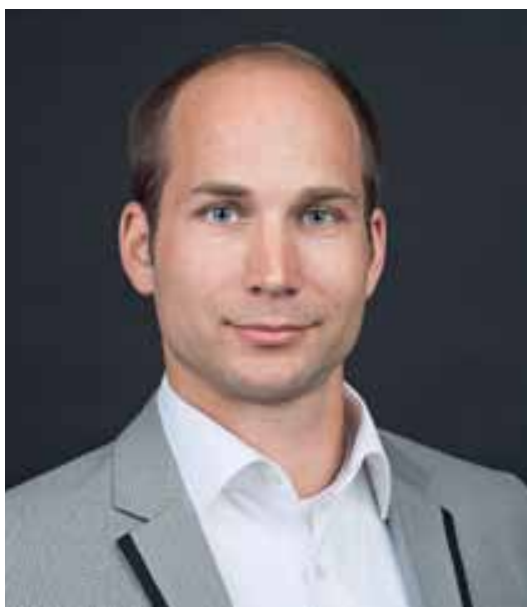

Др. Феликс Хольцнер, СЕО менеджер и сооснователь компании SwissLitho Dr. Felix Holzner, CEO manager, cofounder Swiss Litho
Swiss Litho - молодая высокотехнологичная компания, которая стремится изменить способ производства наноструктур. Их уникальные инструменты для нанолитографии, получившие название NanoFrazor, появились из проекта Millipede от IBM Research Zurich. B запатентованной технологии используются кремниевые наконечники с подогревом для формирования рисунка и одновременной визуализации произвольных наноструктур в высоком разрешении. NanoFrazor открывает новые и беспрецедентные возможности для нанопроизводства, ускоряя научно-технический прогресс во всех областях нанотехнологий. Доктор Феликс Хольцнер любезно отвечает на наши вопросы.

Swiss Litho is a young high-tech company with the vision to change the way nanostructures are commonly made. Their unique nanolithography tools, called NanoFrazor, trace their origins to the Millipede project from IBM Research Zurich. The multiple-patented technology uses heatable silicon tips for patterning and simultaneous imaging of arbitrary highresolution nanostructures. The NanoFrazor opens up new and unprecedented possibilities for nanofabrication in order to accelerate scientific and technological progress in all fields of nanotechnology. Dr. Felix Holzner kindly answers on our questions.
Какие принципы лежат в основе работы вашей компании?

Во время нашей исследовательской работы в IBM в Цюрихе мы обнаружили, что нагретый кремниевый наконечник во много раз эффективнее при нанопроизводстве, чем традиционные технологии наподобие электронно-лучевой литографии. Затем, в 2012 году мы получили патент от фирмы IBM и основали собственную компанию SwissLitho. SwissLitho специализируется на разработке и производстве инструментов и технологий на основе литографии методом термического сканирующего зонда. В этой технологии для испарения резиста используются нагретые ультраострые наконечники для записи наноразмерных структур. После того, как в 2014 году мы основали NanoFrazor, технология приобрела известность, и в настоящее время используется исследователями во всем мире для того, чтобы избежать трудностей, свойственных традиционным инструментам нанолитографии. Многие устройства, обладающие новой геометрией и беспрецедентным качеством производятся с использованием NanoFrazor, что приводит к появлению интересных исследований в публикациях с высоким импакт-фактором.

В чем состоит философия вашей компании, в чем Ваша цель, послание пользователям? Девиз SwissLitho - "Революционизировать нанопроизводство". Мы стремимся сделать термиче- 
скую зондовую литографию обычным инструментом нанотехнологий как в научных кругах, так и в промышленности.

Каковы конкурентные преимущества вашей компании по сравнению с аналогичными продуктами конкурентов?

NanoFrazor - это универсальный инструмент для микро- и нанотехнологий благодаря высокому разрешению и возможности наложения без маркеров. В дополнение к широкому диапазону и точности работы NanoFrazor выделяются возможностью визуализации процесса записи и литографии in situ. Благодаря этому могут создаваться трехмерные наноструктуры. Кроме того, нет необходимости использовать влажную химию для разработки резистов или постоянно корректировать "эффекты близости", свойственные электронно-лучевой литографии. NanoFrazor работает как в условиях окружающей среды, так и в атмосфере инертного газа. Эти характеристики делают NanoFrazor превосходным инструментом для нанолитографии чувствительных материалов, быстрого и точного формирования рисунка электродов на образцах или масках травления, определения сложных массивов фотонных антенн и запуска локальных реакций посредством целевого нагрева в наноразмерном масштабе.

Почему клиенты выбирают продукцию и оборудование именно вашей компании?

Наши клиенты наслаждаются не только надежной работой нашего оборудования и удобным интерфейсом, но и послепродажной поддержкой нашей команды инженеров приложений. Кроме того, мы поняли, что некоторые ведущие исследователи приобретают NanoFrazor только из-за того, что наш инструмент не использует пучок заряженных частиц для нанопроизводства. Эти исследователи использовали дорогостоящие системы с электронным пучком в прошлом, однако электронный пучок может повредить наноразмерные устройства или новые материалы, с которыми они работают.

Какие новые разработки ведутся в вашей компании и когда можно ожидать их внедрение в вашу продукцию? 
Совместно с Heidelberg Instruments мы разработали дополнение DLS (Direct Laser Sublimation). NanoFrazor Explore DLS сочетает термическую зондовую сканирующую литографию с этим дополнением, чтобы ускорить процесс микролитографии для структурирования более крупных объектов. Это расширение вступает в стадию бета-тестирования в Гарварде в США и FZ Juelich в Германии и уже может быть доступно для заказа в конце этого года.

Вы уже имеете опыт взаимодействия с российскими компаниями, как вы оцениваете российский рынок, и в чем его отличия от рынков других стран?

Мы только знакомимся с российским рынком, но наша материнская компания Heidelberg Instruments пользуется здесь большим успехом, поэтому мы с нетерпением ждем возможности изучить этот уникальный рынок. Российские полупроводниковые исследования и промышленность наследуют давние традиции высочайшего качества, и, несмотря на некоторые неудачи, потенциал для инноваций здесь велик. Нам очень любопытно посмотреть, что создадут российские исследователи и инженеры, используя наши инструменты.

\section{Какие инновации вы представляете сегодня} на семинаре?

NanoFrazor является инновационным проектом в самом широком смысле этого слова. Технология термозондовой литографии, которая является сердцем нашей системы, была разработана в IBM и ETH Zurich и не нуждается в дополнительном представлении. Менее чем за десятилетие эта технология стала достаточно зрелой, чтобы стать надежным продуктом, используемым по всему миру для проведения самых современных исследований, опубликованных в лучших журналах. Можно сказать, что наш инновационный продукт используется для проведения инновационных исследований. Кроме того, многие отраслевые партнеры очень заинтересованы в наших технологиях из-за тенденции непрерывной микроминиатюризации.

Как организовано сервисное обслуживание вашей продукции в России?

У нас есть сертифицированные представители - дистрибьюторы в России, а послепродажная поддержка оказывается в нашем офисе в Цюрихе. У нас есть команда инженеров, которые всегда очень рады консультировать наших клиентов по передовым методиками, помочь им разрабатывать новые протоколы, и, конечно, в случае технических проблем наши инженеры прибудут к ним на место в кратчайшие сроки. Мы также пригласили на работу российского ученого с докторской степенью в области нанотехнологий, который также занимается поддержкой российских клиентов.

Какая продукция вашей компании, по-вашему мнению, наиболее приоритетна для российского рынка?

Нам очень интересно посетить несколько конференций Nanotech, чтобы поближе познакомиться с нашими потенциальными клиентами.

Планируете ли вы организовать производство вашей продукции в России?

В данный момент, слишком рано говорить о производстве нашей продукции в России.

Как работает ваша компания в России в условиях экономических и политических санкций? К счастью, Швейцария не ограничена санкциями, которые накладывает на Россию Евросоюз, и мы не видим никаких ограничений в нашем сотрудничестве.

Расскажите, пожалуйста, нашим читателям о сети ваших представительств в России.

Нашими партнерами и дистрибьюторами является компания Minatech...

С какими производителями, университетами, научными центрами или организациями вы работаете в России?

Мы пока не работаем напрямую с российскими производителями или университетами.

Организовывает ли ваша компания образование новичков или сотрудников?

Мы проводим образовательные вебинары и семинары для наших клиентов, например, участвуем в ежегодном семинаре по тепловым зондам в Цюрихе (Thermal Probe Workshop), организуемом SwissLitho и IBM. Мы также обучаем наших сотрудников и поддерживаем их в стремлении получать новые знания и навыки на протяжении всей работы в нашей компании. 